\title{
A HISTÓRIA NA ARTE: UM EXAME CRÍTICO DA SOBREVIVÊNCIA DO GÊNERO HISTÓRICO NA ARTE MODERNA E CONTEMPORÂNEA BRASILEIRA
}

\author{
Renato Palumbo Dória ${ }^{1}$ \\ Maria Madalena Gomes da Silva²
}

O moderno projeto artístico brasileiro, compreendido, sobretudo, a partir da atualização cultural promovida na década de 20; em ressonância com a eclosão dinâmica das primeiras vanguardas européias; buscou romper, de modo programático, com os tradicionais gêneros da representação pictórica (como o retrato, a paisagem, e a pintura histórica, entre outros) - gêneros estes identificados com a tradição acadêmica e, portanto; nos termos de então; com uma concepção estética "passadista", sobretudo no caso específico do chamado gênero histórico.

Efetivou-se assim, notadamente com as primeiras vanguardas internacionais do século XX, uma libertação do sistema dos gêneros e, também, uma dissolução crescente da própria noção de linguagem artística consolidando-se posteriormente uma abertura para a produção de objetos e experiências em um campo de formas híbridas e não usuais. Contexto no qual os chamados movimentos neo-dadaístas; já no âmbito de uma pretensa história da arte contemporânea; dariam prosseguimento a um investimento radical em uma espécie de estética do presente, propondo um permanente salto no "aqui e agora" (fazendo-nos recordar do Instantaneísmo proposto por Francis Picabia), e excluindo assim, ao menos aparentemente, o sentido histórico do âmbito de suas preocupações artísticas e existenciais - apesar de que, nas origens destes movimentos, estivesse, justamente, o arraigado senso histórico de seus formuladores. A ruptura com o passado proposta pelos primeiros modernistas deveria ser de algum modo, também, uma ruptura coma a história.

Este desenrolar mais visível da arte moderna e contemporânea têm a propriedade de encobrir, porém, e de modo sistemático, a permanência e

\footnotetext{
1 Renato Palumbo Dória, Mestre em História da Arte e da Cultura pelo IFCH-Unicamp, e Doutor em Arquitetura e Urbanismo pela Faculdade de Arquitetura e Urbanismo da universidade de São Paulo, é Professor Adjunto de História da Arte na Universidade Federal de Uberlândia.

2 Maria Madalena Gomes da Silva é aluna de graduação em Artes Visuais no Departamento de Artes da faculdade de Artes, Filosofia e Ciências Sociais da Universidade Federal de Uberlândia (Deart/FAFCS/UFU).
} 
sobrevivência de determinadas tópicas artísticas que, se não se constituem efetivamente como sobrevida dos antigos gêneros, ao menos estabelecem, com eles, longos diálogos, nem sempre percebidos, contudo, pela historiografia artística - sendo sintomático deste mecanismo de ocultamento e recalque o fato de que Guernica; uma das pinturas mais emblemáticas da arte moderna do século XIX; seja, justamente, uma grande pintura histórica, cuja figuração narrativa, ainda que constituída por uma nova sensibilidade plástica, não deixa de estar totalmente referendada pela tradição do gênero em questão. Da chamada arte pós-moderna, por sua vez, podemos invocar algo mais próximo, tal como; entre outros exemplos possíveis; o Tiradentes: Totem-Monumento ao Prisioneiro Político, realizado por Cildo Meireles em 1970, em Belo Horizonte, para a exposição De Volta à Terra, com curadoria de Frederico Moraes. Instalação que, ainda que rompendo com os recursos essenciais da figuração narrativa, não deixaria de recorrer, necessariamente no caso em questão, ao referencial histórico:

[...]O fim do figurativismo naturalista na representação do corpo de Tiradentes, iniciado com Pedro Américo e reinterpretado por Portinari, é decretado em um dos trabalhos mais radicais de Cildo Meireles - Tiradentes: Totem-Monumento ao Prisioneiro Político (Exposição De Volta à Terra. Curadoria de Frederico Moraes, 1970, Belo Horizonte). A instalação, segundo descrição de Paulo Herkenhoff, um dos curadores da retrospectiva do artista em Nova York, em 1999, situava-se do lado de fora de uma galeria que se inaugurava: Meireles ergueu um poste vertical de $2,5 \mathrm{~m}$ sobre um quadrilátero marcado por um pano branco. Ele fixou um termômetro no topo. Dez galinhas vivas foram amarradas no poste, molhadas com gasolina e queimadas vivas. Usando o tema da violência como ferida material (chaga, inflamação, carne viva) e referindo-se ao clima nacional de repressão, este gesto terrificante criou profundo desconforto (constrangimento, inquietação) no mundo da arte[...]"3

Ao propormos aqui, portanto, como objeto de análise da obra de João Câmara Filho; o painel Inconfidência Mineira, realizado para o Panteão dos Heróis da Pátria, em Brasília, relacionando-a ainda a outras produções brasileiras que se utilizem do referente histórico; temos como objetivo discutir de modo aberto à sobrevivência e permanência do chamado gênero histórico, defendendo a idéia de que esta permanência e sobrevivência, embora questionável sob diferentes aspectos, é uma das marcas da sensibilidade artística moderna e contemporânea - tanto mais importante e significativa, talvez, quanto menos visível e consciente.

3 WERNECK, Maria Helena. "Representações do martírio de Tiradentes: a performance da morte em público", in REVISTA SEMEAR - revista da Cátedra Padre António Vieira de Estudos Portugueses da Pontifícia Universidade Católica do Rio de Janeiro N.07. 
Uma das características do moderno projeto artístico brasileiro; a partir da atualização pretendida a partir da década de 1920, em ressonância com a eclosão das vanguardas européias do século XX, foi, senão a superação, ao menos a renovação dos tradicionais gêneros da representação pictórica, tais como, entre outros, o retrato, a paisagem e a chamada 'pintura de história' - identificados com uma abordagem acadêmica e, nos termos da época, 'passadista' da arte. O estabelecimento pioneiro, no Brasil, de uma perspectiva cultural 'futurista'; ainda que sob conceituação bastante difusa; pressupunha, justamente, uma idéia geral de rompimento com o passado e de mergulho em direção oposta, investindo-se nas potencialidades desconhecidas do tempo presente e no devir da arte. Tal dinâmica refletia, localmente, a ocorrência efetiva, no plano internacional, de um afastamento radical, alcançado pelas primeiras vanguardas do século $\mathrm{XX}$, das fronteiras dos gêneros - aventurando-se mesmo, algumas destas vanguardas, para além dos limites das linguagens artísticas tradicionais, na produção de objetos e 'obras' que apontavam para um campo aberto de novas formas e meios; território no qual os dadaístas parecem ter se aventurado mais. Já na segunda metade do século passado, por sua vez, os movimentos hoje conceituados como neodadaístas (tais como Fluxus, nouveax-realistes, Pop, etc.); compreendidos no âmbito de uma história da arte contemporânea; investiriam, também, na noção de uma inserção radical no tempo presente, na tentativa conceitual e existencial, através de suas proposições, de um salto para o 'aqui e agora', excluindo, ao menos em sua face aparente, o sentido histórico e narrativo do âmbito de suas preocupações - ainda que, dialeticamente, a origem destes movimentos esteja em grande parte, justamente, no arraigado 'senso histórico' de seus formuladores.

O desenrolar mais visível da arte do século XX; ou ao menos de certa leitura histórica que se tem deste período; parece recalcar portanto a recorrência, nele, da figuratividade narrativa, sendo as múltiplas formas de realismo que se deram ao longo dos últimos cem anos compreendidas, constantemente, e ainda hoje; em vários âmbitos da história e da crítica das artes; como modalidades de 'desvios', de 'regressões' de caráter conservador, como se houvesse, de fato, um sentido único e inequívoco para o desenvolvimento das artes no ocidente - idéia que a própria produção artística contemporânea parece estar desmontando.

A sobrevivência do que chamaremos aqui, em uma acepção bastante aberta, de 'gênero histórico', chegaria até a arte brasileira das últimas décadas tanto de modo diluído e indireto - como na produção da 
pintora carioca Adriana Varejão, que a partir do referente cultural constrói uma espécie de poética matérica do tempo (sobretudo em suas séries de azulejos descarnados ou desgastados), se servindo por vezes de mecanismos de apropriação mais explícitos, como em Estudo sobre Tiradentes (Pedro Américo), exposto na Bienal Internacional de São Paulo em 1998 - ou de modo mais incisivo e circunstanciado, como no caso de algumas das intervenções realizadas por Cildo Meireles em 1970 - como em Quem matou Herzog?; uma de suas Inserções em circuitos ideológicos; ou em Tiradentes: totemmonumento ao preso político - intervenções nas quais, para além do dado eminentemente político há, sobretudo, a imanência de um agudo sentido histórico. Ou seja, sem que o artista retorne ao âmbito restrito de uma 'arte de gênero', ele conecta claramente suas ações artísticas a uma memória política e social coletiva. Memória corporificada por estas ações nas quais tempo presente e tempo passado encontravam-se intrinsecamente indissociados.

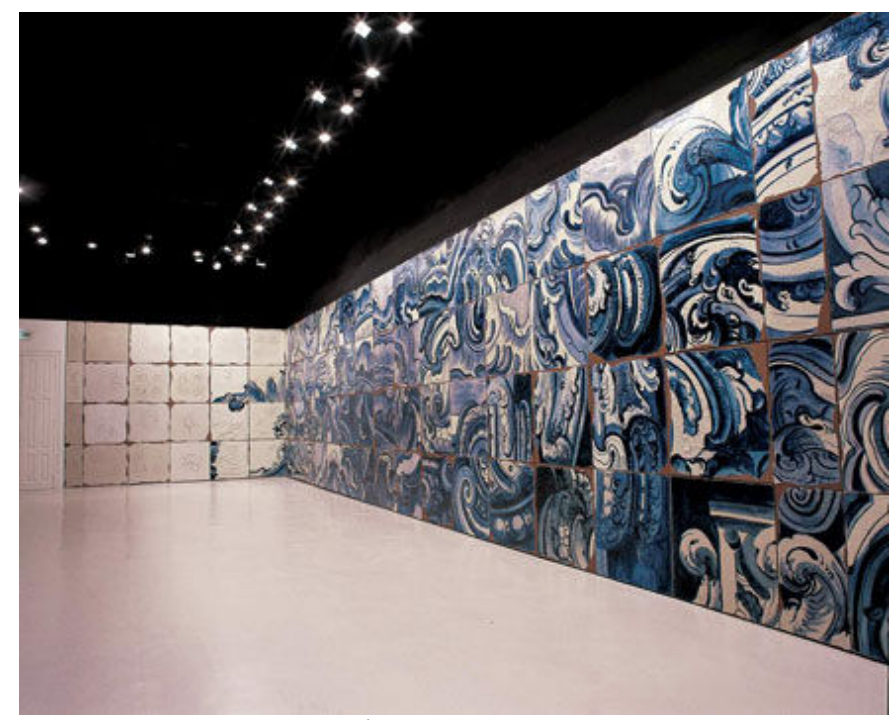

Adriana Varejão

Azulejões. Instalação realizada no Centro Cultural Banco do Brasil, no Rio de Janeiro, 2001

Embora estejamos, portanto, já bastante distanciados, neste contexto, dos sentidos específicos que a chamada 'pintura de história', ou 'pintura histórica', possuiu no século XIX; quando esta se inseria de modo preciso no âmbito do sistema acadêmico de formação e produção artística; 
e que as raízes do gênero possam ser detectadas em muitos séculos e mesmo milênios anteriores; uma de suas constantes será, ainda, seu relativo ajustamento a contextos políticos específicos, servindo como discurso de construção ou de questionamento identitário e, também, como estratégia de poder e resistência. Não se trata apenas, enfim, da construção de imagens alegóricas ou narrativas 'sobre a história', ou 'a partir da história', pois o que se dá é sempre, em ultima instancia, um discurso sobre o próprio presente.

É a partir destas considerações preliminares que situamos a realização, pelo pintor paraibano João Câmara Filho, do painel Inconfidência Mineira, obra de 21 metros de comprimento por 4 metros de altura realizada em acrílico sobre tela, em preto e branco, entre 1985 e 1986 para o salão principal do Panteão da Pátria Tancredo Neves, (ou simplesmente Panteão dos Heróis da Pátria) em Brasília. Painel e conjunto arquitetônico; constituído de outras obras artísticas; que, encomendados durante o primeiro governo civil brasileiro após o ciclo militar das décadas de 1960 e 1970, podem ser lidos, primeiramente, como monumento em homenagem à própria redemocratização do país ocorrida na década de 1980. Esta leitura, porém, é insuficiente para compreenderem-se outras intencionalidades existentes na concepção e materialização dos objetos em questão, sendo o próprio convite feito ao pintor João Câmara Filho para a realização do painel um dado significativo, na medida em que o artista já vinha desenvolvendo anteriormente, com certo sucesso, uma serie de pinturas narrativas nas quais o drama político contemporâneo era explicitado através da construção de imagens emblemáticas, sobretudo da tortura, presentes, por exemplo, na série Cenas da Vida Brasileira, 1930-1954, exposta em 1976, ou em obras como Friendly persuasion, de 1970, ou Uma confissão, de 1971.

Se, sob este viés, a ligação entre o painel Inconfidência Mineira e o conjunto da produção imediatamente anterior do artista é bastante evidente - em uma operação artística e simbólica na qual os inconfidentes não se encontram no passado, mas sim vivificados e irmanados pelo sangue e pela dor dos novos mártires contemporâneos - é para as intencionalidades políticas dos usos de tal operação que devemos estar atentos, sendo necessário compreendermos, também, como ainda na década de 1980 a poética de João Câmara Filho será uma das poucas, no país, a servir a este gênero de discurso. Percebido então, neste período, como artista relativamente 'desatualizado', deslocado de algum modo em relação a seus contemporâneos; justamente por seu apego à narração figurativa de cunho político e social, abandonada por muitos de sua geração; a obra de João Câmara Filho sempre terá possuído, no entanto, grande singularidade, 
guardando distância da de outros artistas mesmo quando estes sentiram, sobretudo nas décadas de 1960 e 1970, a necessidade de um retorno à figuração, como no caso de um Ivan Serpa - pioneiro do abstracionismo geométrico no Brasil. Singularidade, 'desatualização', distanciamento e deslocamento que pretendemos seguir investigando, com interesse, ao longo da pesquisa aqui apenas introduzida.

\section{Bibliografia}

AMARAL, Aracy. Arte para quê? a preocupação social na arte brasileira 1930-1970. $2^{a}$ ed. rev. SP: Nobel, 1987.

CHARTIER, Roger. História cultural - entre práticas e representações. Rio de Janeiro: Bertrand Brasil, 1990.

FABRIS, Annateresa. Portinari, pintor social. SP: Perspectiva, Edusp, 1990. Coleção estudos. - (org.). Modernidade e modernismo no Brasil. Campinas, SP: Mercado das Letras, 1994. Coleção arte: ensaios e documentos.

. "A questão futurista no Brasil" in BELLUZZO, Ana Maria de Moraes (org.) Modernidade: vanguardas artísticas na América Latina. São Paulo, Memorial: UNESP, 1990.

MORAIS, Frederico. Nota biográfica. Inb: CENAS da vida brasileira, 1930/1954: 10 pinturas e 100 litografias de João Câmara Filho; Recife: Prefeitura; Fundação Roberto Marinho; Grupo Othon, 1980.

O OLHO de João Câmara sobre as cidades. Continente Multicultural, Recife, ano 1, n.0, p.16-47, dez. 2000 .

ORTIZ, Renato. Cultura brasileira e identidade nacional. São Paulo: Brasiliense, 1994.

A moderna tradição brasileira. São Paulo: Brasiliense, 1988.

PANORAMA DA ARTE BRASILEIRA. São Paulo: MAM, 2006.

PEDROSA, Adriano. Azulejões. Centro Cultural Banco do Brasil, Rio de Janeiro 2001

PEDROSA, PEDROSA, Mário. Dos murais de Portinari aos espaços de Brasília. São Paulo: Editora Perspectiva, 1981.

REYERO, Carlos. L A PINTURA DE HISTORIA EM ESPAÑ A. Madrid: Cátedra, 1989.

STAROBINSKI, Jean. 1789: Os Emblemas da razão. São Paulo: Cia das Letras, 1998. Fontes, 1992.

ZILIO, Carlos. A querela do Brasil: a questão da identidade da arte brasileira: a obra de Tarsila, Di Cavalcanti e Portinari/ 1922-1945. Rio de Janeiro: Funarte, 1982. 